\title{
ADAPTAÇÃO MARGINAL DE UMA RESINA COMPOSTA: EFEITO DE SISTEMAS DE FOTOATIVAÇÃO
}

Giovana Mongruel GOMES; Osmara Maria Mongruel GOMES; João Carlos GOMES; Abraham Lincoln CALIXTO; Gislaine Cristine MARTINS

A contração de polimerização é o maior problema na adaptação marginal das restaurações em resina composta fotopolimerizável, causando a formação de fendas marginais. O objetivo foi avaliar a formação destas fendas em restaurações de resina composta classe II, utilizando um aparelho à base de lâmpada halógena (QTH), e dois à base de LEDs. Cavidades padronizadas foram executadas nas faces proximais de 18 terceiros molares humanos. Resina composta Filtek P60 (3MESPE) foi inserida por meio de uma ponta fotocondensadora e fotoativada usando três sistemas de fotoativação: GI-Optilux401 (QTH); GII-ColtoluxLED (LEDs) e GIII-UltraLumeLED5 (LEDs). Após o acabamento os dentes foram submetidos à ciclagem térmica à $5^{\circ} \mathrm{C}+2^{\circ} \mathrm{C}$ e $5^{\circ} \mathrm{C}+2^{\circ} \mathrm{C}$, realizando um total de 500 ciclos. Os dentes foram seccionados no sentido vestíbulo-lingual e depois no centro das restaurações. A extensão da fenda foi observada sob MEV com um aumento de 1000X. Os dados foram analisados através do teste não paramétrico de Kruskal-Wallis. Os m; Glluvalores médios da amplitude das microfendas foram: Gl 3.28+3.34 m. Concluiu-se que fendas marginais foram $\mu \mathrm{m}$ e GIII $3.11+3.45 \mu 1.48+1.89$ observadas em todos os grupos; e entre os aparelhos de fotoativação utilizados neste estudo não houve diferenças estatísticas significantes, apesar de uma tendência de melhor desempenho para o Gll. 